\title{
EL COMERCIO CATALAN CON ORIENTE
}

GASPAR FELIU

Universidad de Barcelona

En la historiografía catalana el comercio con Oriente es un tema tan clásico como dado por sabido sin sentir la necesidad de profundizar en la investigación ni de revisar los tópicos acumulados ${ }^{1}$. Mientras la mayor parte de los mitos políticos nacionalistas han sido objeto de profundas revisiones, los mitos económicos, menos incómodos, han quedado intactos. Tan intactos en el caso del comercio con Oriente, que no existe ninguna obra dedicada específicamente al tema y que el estudio básico, la obra de Antonio de Campmany, fue publicada el año $1779^{2}$; posteriormente han aparecido otras investigaciones, pero el comercio con Oriente no es su tema central (como tampoco lo era en Campmany), sino que es tratado con referencia a otras cuestiones ${ }^{3}$.

Estas notas no pretenden llenar el vacío, sino exponer solamente algunas reflexiones surgidas de la lectura o de la relectura de lo que se ha escrito, en el intento de dar una visión muy general del comercio catalán en el contexto europeo y también en el contexto de la política de la Corona de Aragón.

Para ello hemos dividido la exposición en tres partes, bastante desiguales en cuanto a su extensión, dedicadas la primera a las características generales del comercio catalán con Oriente, la segunda a los diversos momentos y rutas que se pueden distinguir en dicha actividad comercial y la última a examinar las interacciones reales o supuestas entre política y economía en la expansión mediterránea.

' El presente trabajo procede de una conferencia, bajo el título $*$ El comerç català amb el Mediterrani Oriental (segles XIV i xv)», dictada en el Instituto de Geografía, Etnología e Historia del CSIC de Barcelona, en marzo de 1984, dentro del cursillo «Aproximació teòrica i documental al comerç català a la Baixa Edat Mitjana*.

2 Algo parecido sucede con el comercio de Oriente en su conjunto: el libro que sobre el tema escribió Heyd en 1879 continúa siendo la síntesis básica.

${ }_{3}$ Principalmente: Nicolau (1926), Rubió (1947), Masià (1951), Coll (1954), Carrère (1967), Del Treppo (1972), Madurell y García Sanz (1978), García Sanz y Ferrer (1983). 


\section{Características generales del comercio catalán con Oriente}

Es bien sabido que el comercio oriental estuvo a lo largo de la edad media dominado por dos potencias: Génova y Venecia. Venecia frecuentaba los puertos de Egipto y Palestina ya antes del año 1000; Amalfi poseía antes de esta fecha un alfóndigo en Alejandría; la presencia genovesa está atestiguada desde 1065, si bien debió su auge a la primera Cruzada (1095-1099). En este momento en Cataluña todavía no se había conquistado Balaguer ni repoblado Tarragona, ni casi soñado con conquistar las Baleares; sin embargo, la primera mención de mercaderes catalanes en Oriente, concretamente en Trípoli de Siria, se remonta al año $1111^{4}$; aunque la primera mención de naves catalanas en la misma ruta no aparece hasta la segunda mitad del siglo xII, momento en que Benjamín de Tudela señala su presencia en Alejandría. Los catalanes llegaron, pues, relativamente tarde al comercio oriental y nunca pasaron de ser en él una potencia de segunda fila. Una segunda fila distinguida, sin duda: según Robert S. Lopez (1971) en el siglo xIv sólo Venecia y Génova, y en un tono menor Barcelona, estaban realmente equipadas para el comercio con Oriente ${ }^{5}$. Y si bien Barcelona quedaba muy atrás respecto a Venecia o a Génova, también es verdad que estaba muy por encima de las otras ciudades italianas u occitanas; sólo Mallorca estuvo casi a su altura en un momento dado.

La necesidad de sintetizar y a veces también el deseo de acumular han provocado una imagen demasiado lisonjera del comercio catalán con Oriente. Pienso por ejemplo en aquellos mapas donde se muestran todos los consulados catalanes en el Mediterráneo sin advertir que, si bien todas aquellas ciudades tuvieron cónsules de los catalanes, no todas los tuvieron a la vez $y$ que en muchos casos el consulado fue un hecho tardío, efímero y en ocasiones encargado a personajes no catalanes; por no hablar de los mapas que muestran la expansión mediterránea de la Corona de Aragón callando que todos aquellos dominios no fueron tampoco nunca dominados conjuntamente, que alguna de las conquistas más extensas fue muy tardia (Nápoles) o más teórica que real (Córcega y gran parte de Cerdeña) ${ }^{6}$.

4 Una noticia publicada hace pocos años (Airaldi, 1983), referente a los documentos hallados en la Geniza de El Cairo, podría hacer pensar en que los catalanes hubiesen llegado ya a Oriente hacia 1060-1070, momento en que un judío de Alejandría escribía a su hermano residente en El Cairo notificándole la llegada de naves de las tierras de los Rum, de Génova y de otros lugares, añadiendo que se decía que estaban a punto de llegar naves de España. Si eran naves de Rum, o sea, de cristianos, habían de ser catalanas; sin embargo, parece más posible que se tratase de embarcaciones de Al-Andalus.

${ }^{5}$ No obstante, Heers (1963) pudo escribir todo un libro sobre el tema sin referirse para nada al comercio catalán; quizá su patriotismo le impulsó a continuar de esta forma la guerra medieval entre Génova y Barcelona.

Durante la mayor parte del siglo XIII, desde su conquista (1232) a la muerte de 
Aunque los catalanes no estuviesen en primera fila del comercio oriental, éste era sin duda primordial para su economía y muy especialmente para su comercio; si pudo haber una ruta comercial occidental, si se pudo crear una industria importante, básicamente textil, pero también de cuchillería, platería o elaboración del coral, fue porque hubo un comercio con Oriente. Bien lo sabían los contemporáneos: el Consell de Cent afirmaba el año 1453 que el comercio con Oriente era «Foment, cap e principi de tot negoci; perturbats los affers de Llevant, en gran part son desviats tots los altres» (Campmany, 1779: IV, doc. CXXIV); y ello no por su volumen, sin duda inferior al comercio con el Mediterráneo occidental, sino porque el comercio con Oriente permitía redondear el negocio también con Occidente, permitía remontarse del intercambio regional al gran comercio y crear una importante actividad manufacturera; en definitiva, mantener la prosperidad de la economía catalana. Tal era su importancia que Arcadi García ${ }^{7}$ dice muy acertadamente que el comercio catalán medieval se estructuró como una larga ruta primordial, la ruta hacia Oriente, y una serie de rutas derivadas, de forma que la decadencia de la ruta de Levante en el siglo xv provocó la caída en picado del comercio catalán en su conjunto.

Para entender las características más generales de este comercio puede ser útil ponerlo en comparación con el de la mayor potencia naval de la época, o sea Venecia. Mientras el comercio veneciano se organizaba en grandes expediciones oficiales (mute), verdaderas armadas de galeras hacia los principales puertos de Oriente, de donde volvían cargadas básicamente de especias, el comercio catalán se caracterizaba por la falta de cualquier control o iniciativa oficial, por la presencia de un hormiguero de iniciativas, por la importancia secundaria de los viajes directos (que incluso cuando se presentaban como tales realizaban numerosas escalas) respecto a los viajes y al comercio indirectos. El comercio catalán típico se define mal como una ruta y mejor le convendría la comparación con una tela de araña; era un comercio

Jaime I (1276), Mallorca estuvo unida a la Corona, pero no lo estaba cuando se produjo la conquista de Sicilia (1282), que, a su vez, se convirtió casi inmediatamente en reino independiente (1285), justo el mismo año que Mallorca era arrebatada a la dinastía colateral que la regía. En 1291, también Sicilia volvía a manos de la Corona, pero este primer momento de dominio sobre el conjunto de la diagonal fue de escasa duración: Sicilia volvió a ser independiente en 1295 , y Mallorca, en 1298 . Hasta la conquista de Cerdeña, en 1323, la Corona de Aragón no dominó ninguna de las grandes islas mediterráneas. Cerdeña quedó en el futuro unida a la Corona y, aunque gran parte de la isla estuvo casi constantemente sublevada, los principales puertos fueron mantenidos. En 1343, Mallorca fue anexionada definitivamente, y en 1409 lo fue Sicilia. Sólo, pues, para el siglo xv fue real el dominio de la diagonal de las islas. De los otros territorios, Córcega fue dominada parcialmente tan sólo entre 1404 y 1453, y la conquista de Nápoles, empresa personal del rey llevada a cabo en contra del parecer de las clases dominantes en Cataluña, no se completó hasta 1443.

7 Estudio introductorio a Madurell y García Sanz (1973: 20-21). 
que avanzaba de puerto en puerto, inquiriendo noticias, desviándose fácilmente de su ruta, vendiendo y comprando mercancías en las escalas intermedias; este ir avanzando $e$ ir realizando compraventas sucesivas era necesario para poder llegar a Oriente con capitales suficientes, en parte acumulados gracias a los repetidos intercambios.

Por otro lado no hay que olvidar la existencia en Oriente de colonias de mercaderes especializados en el tráfico entre el interior y los puertos o entre los puertos secundarios y principales, mercaderes que raramente volvían a su país de origen y que aseguraban la parte más arriesgada del comercio oriental. Mercaderes que encontramos en naves de cualquier nacionalidad y que naturalmente compraban y vendían a todos, pero a los cuales podemos suponer una cierta tendencia a relacionarse con sus connacionales.

Finalmente - pero en este aspecto la diferencia con las grandes potencias comerciales de la época es sólo cuantitativa-, el comercio catalán era un comercio de redistribución, con cuatro destinos principales: Africa del Norte, Occitania, Aragón y más tarde quizá Navarra y la Meseta Norte y también el mundo atlántico.

\section{Diferentes momentos $y$ caminos}

El comercio con Oriente no fue, claro está, un proceso uniforme y los cambios que se dieron tanto en su volumen como en las rutas o en las mercancías transportadas dependian de la situación interna en Cataluña o en la Corona de Aragón y de la situación en el Mediterráneo occidental, pero sobre todo, hecho que se suele tener menos presente, de la situación en Oriente.

La coyuntura económica interior parece haber sido cada vez más favorable hasta mediados del siglo xIv. Todas las peticiones de hombres y capitales para la expansión habían sido aceptadas hasta que a mediados del siglo xIV Pedro el Ceremonioso empezó a tener problemas para financiar sus empresas. Continuaban existiendo grandes fortunas, pero en conjunto el país mostraba dificultades para mantener el ritmo ascendente de la etapa anterior. Dificultades que irían en aumento y que llegarían a su punto máximo con la guerra civil de $1462-1472^{8}$.

En el Mediterráneo occidental los hechos que podían afectar al comercio con Oriente eran básicamente la situación en el Norte de Africa y la correlación de fuerzas en Italia. En el norte de Africa los catalanes rivalizaron con castellanos y genoveses a lo largo de los siglos xill y xIV, pero posteriormente, con la conquista de Sicilia, ejercieron sobre Ifriquiya un claro

\footnotetext{
- Sigo la periodización de Vilar (1956), incorporada a su obra de 1962.
} 
dominio, un verdadero protectorado en muchos momentos, especialmente durante los años en que dominaron la isla de Djerba (1284-1335); a partir de esta última fecha su situación fue mucho menos predominante (Dufourcq, 1960). Por lo que respecta a Italia, los catalanes, desde el punto de vista militar, consiguieron imponerse en el sur, a pesar de la oposición genovesa y francesa, no sin largas luchas. La resistencia genovesa impidió el dominio efectivo sobre gran parte de Córcega y de Cerdeña, y la larga guerra, llevada a cabo sobre todo por corsarios, comprometió el futuro de ambas potencias y especialmente el de sus marinas, aunque la genovesa mostró mayor capacidad de reacción que la catalana.

De todos modos la importancia de las coyunturas occidentales no debe hacernos olvidar que el comercio con Oriente venía determinado sobre todo por los acontecimientos que sucedían allí mismo e incluso en el interior de Asia. Vamos, pues, a repasarlos rápidamente. Mientras duró el califato de Bagdad y sobre todo bajo el dominio fatimí de la fachada oriental mediterránea, de Siria a Egipto, los musulmanes imponian su predominio económico en el Mediterráneo, pero los cristianos podían comerciar y visitar Jerusalén con relativa tranquilidad. Mientras tanto, en el interior de Asia los pueblos turcos habían iniciado su expansión en dos direcciones: hacia el sur de Rusia y hacia Mesopotamia. En el primer caso una serie de invasiones dificultaron la vía comercial que unía las costas del mar Negro con el Asia central, hecho que determinó la decadencia de Bizancio. En el segundo, la infiltración de los seljúcidas en el imperio de Bagdad, que acabarían dominando, tuvo tres consecuencias principales: inició el establecimiento de los turcos en Anatolia, a costa de Bizancio, después de la batalla de Mazinkert (1071); provocó la decadencia económica del mundo oriental, víctima de la combinación de destrucciones, impuestos y arbitrariedades aportada por los invasores, y dificultó el comercio mediterráneo y con él la visita de los cristianos a Jesusalén, conquistada también en 1071. La nueva situación económica y religiosa dio pie a la primera cruzada y con ella al dominio cristiano de casi toda la fachada oriental mediterránea, a excepción de Egipto.

La presencia catalana en Oriente, continua y bien documentada, fue posterior a estos hechos. Intentaremos dar una periodización un poco detallada, fijándonos en los procesos que provocaron cambios de importancia. De entrada podemos distinguir tres grandes etapas: de formación, hasta finales del siglo XIII; de prosperidad, hasta mediados del siglo xv; y posteriormente, de decadencia. Con dos momentos de crisis y transformación: 1291-1338 y 1415-1462.

La primera etapa va de mediados de la segunda mitad del siglo XII hasta 1260 . Son años de aprendizaje. Aunque no se ha dicho,_quizá por orgullo 
nacionalista, parece claro que los comerciantes catalanes llegaron a Oriente más tarde que los mercaderes de Provenza y del Lenguadoc y puede que a remolque de éstos. Tanto en Tiro como en Alejandría o en Constantinopla los encontramos compartiendo los mismos barrios o alfóndigos o recibiendo privilegios conjuntamente ${ }^{9}$; y si bien ya en 1219 encontramos al conde de Ampurias comerciando con Oriente, su nave estaba matriculada en Marsella ${ }^{10}$. Precisamente uno de los problemas pendientes de explicación con referencia al comercio catalán con Oriente es cómo logró superar a las ciudades occitanas para acabar dominando durante largo tiempo la redistribución de mercancías orientales en la zona. Para el Lenguadoc podemos pensar en los efectos de la cruzada antialbigense, pero para Provenza, con puertos como Marsella o Aigües Mortes, no encuentro una explicación suficientemente satisfactoria. Como acta de independencia del comercio catalán respecto al occitano podría quizá considerarse la decisión de Jaime I en 1227 (dos años antes de la expedición a Mallorca) de prohibir embarcar mercancías destinadas a Oriente en naves extranjeras mientras hubiese naves catalanas disponibles. Esta verdadera acta de navegación (Vilar, 1962: II, 82) puede ser interpretada como un intento de asegurar a las naves catalanas una carga suficiente, que animara a emprender el viaje.

En esta primera etapa la llamada ruta de Ultramar, o sea los viajes con destino a los puertos cristianos de Palestina y a Alejandría, era la más frecuentada; la finalidad de este comercio parece haber sido casi exclusivamente la traída de especias, hasta el punto que los derechos sobre «les coses exportades de Alexandria» que figuran en el libro del Consulat del Mar, se limitan a la enumeración de toda clase de especias. Para poder financiar los cargamentos de vuelta se exportaban básicamente paños, franceses o flamencos y algunas veces del país, y también aceite, pero para saldar el viaje a menudo era necesario aportar numerario. En esta época los viajes catalanes acababan alguna vez en Constantinopla, pero por lo que sabemos, la decaída capital del Imperio Latino de Oriente no resultaba un mercado demasiado importante (Madurell y García Sanz, 1978: 24).

De 1260 a 1290 el comercio catalán con Oriente experimentó una primera etapa de clara expansión, testimonio de la cual es la primera formación de consulados, muchas veces creados tras de los genoveses a base de reclamar de las autoridades locales las mismas prerrogativas concedidas a aquéllos. El hecho más significativo es quizá la obtención de un alfóndigo y consulado en Alejandría, dotado incluso de notario nombrado por Jaime I, todo lo

- En 1187, Conrado de Montferrat concedió privilegios en Tiro a las colonias de comerciantes de Barcelona, Montpeller, Saint Gilles y Marsella.

${ }_{10}$ Conviene recordar que, hasta 1246, Provenza estuvo unida a la Corona de Aragón o regida por ramas colaterales de la dinastía. 
cual costó diez años de negociaciones (1262-1272) y provocó entre tanto el abandono de la cruzada iniciada por Jaime I en 1269 (Madurell y Garcia Sanz, 1978: 23). También durante estos años se obtuvieron privilegios en Constantinopla y poco después en Chipre.

La expansión hacia Oriente surgió de la expansión en el Mediterráneo occidental. Estos fueron los años de guerra entre Venecia y Génova (12681297) que los catalanes pudieron aprovechar actuando como pabellón neutral; fueron sobre todo los años de las primeras intervenciones en Ifriquiya (Dufourcq, 1966: 86-87), coronados con el dominio sobre Sicilia (1282) que permitió controlar gran parte del comercio de la isla y del comercio con el norte de Africa. Pero los cambios más importantes tuvieron lugar en Oriente con la implantación de la llamada paz mongol. Las sangrientas campañas de Genghiskan y de sus sucesores unificaron en la destrucción todo el espacio entre la estepa rusa, el mar de China y el golfo Pérsico; con la conquista de Bagdad en 1258 solamente escaparon al poder mongol dos acantonamientos islámicos: los turcos seljúcidas de Anatolia y los mamelucos de Egipto. En uno y otro caso la civilización y la economía musulmana quedaron sepultadas bajo despóticos dominios de castas militares que ejercían una explotación impositiva ruinosa para la mayor parte de la población.

Sin embargo, tras el primer momento de destrucciones, la paz mongol resultó favorable para el comercio: una ruta organizada y pacificada atravesaba desde el mar Negro hasta China y también por Persia hacia la India. Para las potencias occidentales el beneficio fue doble: en el norte, incremento del comercio con China y recuperación de Constantinopla como importante centro consumidor; en el sur, predominio total en el mar (ni turcos ni mongoles ni egipcios eran pueblos marineros) y posibilidad de colocar más productos en Oriente, dado el encarecimiento que los impuestos representaban para la producción local.

Este momento de impulso general dio paso, a partir de 1291, a una etapa de cambios rápidos, etapa que podemos considerar terminada en 1338. Las causas fueron, una vez más, políticas. En 1291 el sultán mameluco asaltó el último reducto continental de los estados cruzados: San Juan de Acre. Como respuesta el papa prohibió el comercio con los territorios del sultán de Babilonia, nombre que se daba al soberano egipcio. En principio la prohibición afectaba al comercio de productos estratégicos (armas, caballos, hierro, madera, alimentos), pero en 1308 se amplió a todo el comercio con los territorios del sultán: Egipto y la fachada oriental del Mediterráneo.

Los occidentales hicieron frente a la nueva situación incrementando el comercio con el mar Negro y las rutas mongoles y retrocediendo a posiciones insulares defensivas: Chipre, donde fue restaurado el reino de Jerusalén y 
donde se refugiaron muchos fugitivos de San Juan de Acre; Rodas, ocupada y fortificada por la Orden del Hospital (1410); Quíos, convertida por los genoveses en emporio de su comercio con Oriente. Ante la potencia militar y la brutalidad de turcos y mamelucos el mar se había mostrado, y se mostraría durante mucho tiempo, como la mejor defensa. La retirada no fue sólo territorial, sino también comercial: muchos mercaderes prefirieron fijar su residencia en las islas y viajar en todo caso desde allí a los puertos musulmanes; de esta forma se disminuía el peligro y se ponía al menos a cubierto la familia. Igualmente muchos viajes tendieron a acabar en Rodas o en Chipre. Por otra parte se continuó comerciando ilegalmente o indirectamente con las tierras prohibidas, prescindiendo de los anatemas papales (Trenchs, 1980).

Estos fueron también los años de la célebre expedición de los almogávares a Oriente (1303). Desde el punto de vista económico, la parte positiva de la operación fue el mantenimiento de las costas del Egeo en manos cristianas y el alejamiento de los turcos seljúcidas de Constantinopla. En la parte negativa hay que considerar el horrible recuerdo dejado en Bizancio, donde hasta la generación siguiente no parece que ningún mercader catalán osara acercarse; y también seguramente la estela de piratería que colaboraron a crear o a alimentar. En cuanto a los ducados de Atenas y de Neopatria, carecían de interés comercial.

Hemos dicho que dejando aparte un comercio ilícito residual, la prohibición papal (pero no sólo la prohibición papal) desvió a los mercaderes cristianos hacia el norte. No a todos: los catalanes continuaron viajando a Ultramar. Sus reyes estaban excomulgados desde la conquista de Sicilia y por tanto no les venía de una excomunión más; y precisamente en 1290 acababan de firmar un tratado de paz con el sultán. Según Robert S. Lopez (1952), la prohibición papal de comerciar con el territorio mameluco favoreció al comercio catalán, que hizo caso omiso de la prohibición. En cambio, Del Treppo (1972: 23-24) opina que el rompimiento diplomático marcó una etapa de retroceso.

En 1302 la reconciliación de Jaime II con el papa comportó la prohibición de comerciar con Egipto, que, sin embargo, no parece haber sido seguida con gran rigor: el consulado de Alejandría no fue cerrado en ningún momento (Nicolau, 1926: 35-36). Ciertamente el miedo a las penas espirituales o materiales hizo disminuir el comercio directo, pero parece que en grado menor que en otros países (Venecia dejó de mand̦ar sus flotas a Alejandría durante veinticinco años). Podemos concluir, pues, que tanto Lopez como Del Treppo llevan parte de razón. Si la prohibición, a pesar de no ser demasiado rígida, no hubiera comportado dificultades, el Consell de Cent no habría 
sobornado al rey (1338) para que sobreseyera todas las causas contra mercaderes acusados de comerciar con Egipto; el monarca se embolsó 1.000 libras y se conformó con imponer una tasa al comercio prohibido; el papado prácticamente actuaba igual, ya de tiempo atrás (Trenchs, 1980).

Queda, con todo, otro aspecto que enmascara la disminución del comercio denunciada por Del Treppo: correlativamente a la instalación de las fortalezas insulares que ya hemos citado, vemos aparecer una nueva organización comercial; en adelante los viajes tendian a terminar en Chipre o en Rodas, donde se podían obtener las mercancías orientales, compradas a traficantes, entre los cuales encontramos un nutrida colonia catalana, especializados en la parte más peligrosa: las rutas entre los puertos de Siria o de Egipto y las islas.

La etapa se caracteriza, pues, por el comercio directo con Chipre, e indirecto o ilegal con Alejandría, y por la práctica desaparición de las rutas de Romanía, o sea, del Imperio bizantino. En conjunto hubo un cierto retraimiento o al menos lo que hoy denominaríamos como crecimiento cero. Por lo que respecta a las mercancías, eran las mismas que en las etapas anteriores, con una innovación importante: se empezó a importar algodón, tanto de Chipre como de Armenia.

El alzamiento fáctico en 1338 de la prohibición real para comerciar con Siria y Egipto puede ser considerado como el inicio del gran momento del comercio oriental catalán. El problema se plantea al intentar delimitar el punto final de esta etapa. Madurell y Garcia Sanz (1978: 28-29), basándose en las comendas conservadas, creen que hubo un rompimiento irreversible hacia 1415; también Claude Carrère (1967: II, 220-222) habla de crisis evidente en relación con 1420 , si bien considera que el comercio se mantuvo bien hasta 1440. En cambio, para Del Treppo (1972: 34-39) la crisis de 1415 fue un fenómeno puntual, seguido de una fuerte recuperación, de forma que el punto máximo del comercio oriental catalán se alcanzaría hacia 1435 , aunque la decadencia no sería evidente hasta los años cincuenta, y en definitiva sería la guerra civil (1462-1472) lo que provocaría que la decadencia comercial resultase irreversible.

Por razones básicamente de comodidad narrativa, me adheriré provisionalmente a la propuesta de Madurell y García Sanz y consideraré como etapa de plenitud del comercio catalán los años que van de 1338 a 1415 . Durante estos años se puede hablar de inicio de decadencia o de dificultades en Cataluña (Peste Negra, guerras con Castilla, sublevaciones nobiliarias de las Uniones aragonesa y valenciana, malestar de los payeses de remensa, quiebra de los grandes banqueros) y también en el Mediterráneo occidental: pérdida de Djerba poco antes (1325), hostilidades con Génova (la otra guerra de los 
Cien Años), pero todo ello no parece que obstaculizase, al menos de momento, el comercio con Oriente, que tomó una gran altura y su más plena conformación, esencialmente cuando en 1353 se obtuvo del sultán un trato aduanero igual al que disfrutaban Génova y Pisa y mejor que el concedido al resto de países. De tal forma que cuando se habla del comercio catalán con Oriente se acostumbra a ampliar a toda la Edad Media las características en esta etapa de plenitud. Características que son principalmente: a) la presencia en numerosos puertos y ciudades del interior, desde el mar de Azov hasta Alejandría, remarcada por la existencia de consulados en los centros o encrucijadas principales, con un volumen de tráfico comercial superior al de las etapas anteriores; $b$ ) la comercialización de un gran número de productos, en proporción importante manufacturas catalanas a la ida y destinados a la reexportación a la vuelta; c) el uso de unas técnicas y de una legislación comercial típicas, punto que no podemos sino señalar y que por otra parte ha sido suficientemente estudiado (Sayous, 1975; Madurell y García Sanz, 1978; García Sanz y Ferrer, 1983).

La ampliación del tráfico no es demostrable directamente, pero surge con claridad de la observación de cualquier tipo de indicador, ya sean las comendas, los seguros o el número de barcos documentados en los puertos orientales. Más fácil resulta establecer una lista de los lugares y puertos visitados y de aquellos que contaban con una colonia fija o pasajera lo bastante numerosa como para poder mantener un consulado. Destacaré solamente la presencia consular en Beirut desde 1344, consulado trasladado a Damasco en 1379, y también los asentamientos de Pera, en Constantinopla (consulado desde 1383), Quíos (1404) y Candía (1419) ${ }^{11}$.

También es de este momento la concentración de gran parte del comercio catalán en Rodas: la isla de los Hospitalarios era una parada segura y obligada antes de entrar en el mundo oriental, donde las situaciones políticas podían cambiar tan rápidamente; por otra parte, desde Rodas se podía ir tanto hacia Romanía como hacia Egipto o Siria, y además muchos comerciantes y sobre todo muchas naves se contentaban con recoger en Rodas los productos aportados por todas las rutas de Oriente. Según los datos de Del Treppo, que no hay que entender como una lista completa, pero que pueden ser utilizados como indicador grosero de la situación, de 1390 a 1417 viajaron a Alejandría 61 naves, a Siria 55 (de ellas 29 a Beirut y 18 a Chipre) y a Romanía 44, de ellas 30 a Rodas (Del Treppo, 1972: 68-74).

Pero quizá más que en los puertos visitados, la principal novedad radi-

"De todos modos, los consulados han gozado de mayor fama de la merecida: en Alejandría y Damasco hubo largas series de cónsules catalanes, pero en Constantinopla, Chipre, Quíos, etc., el cargo estuvo casi siempre en manos de comerciantes extranjeros (Voltes, 1964). 
caba en los productos comercializado: en esta etapa, sin dejar de exportar los paños extranjeros (franceses, ingleses, flamencos), el comercio catalán daba salida a mucha producción propia. En primer lugar, paños, no una pañemercados orientales (Ashtor, 1976). En segundo lugar, coral, obtenido principalmente en Cerdeña, pero trabajado en Barcelona. En tercer lugar, aceite, miel, frutos secos y azafrán; más secundariamente, productos de cuchillería, planchas de cobre y productos cosméticos, como el alcohol (alcofoll), sulfuro de antimonio, polvo azul usado como base para colirios y maquillajes, o de perfumería (violetas).

A esta diversificación de las exportaciones correspondía una diversificación también de los productos importados: las especias y algunos tejidos de lujo continuaban siendo la base del comercio con Alejandría y Siria, pero a partir de Rodas la revitalización del comercio con Romanía (muchas veces simplemente con el emporio genovés de Quíos) permitía obtener importantes materias primas: esclavos blancos (rusos, búlgaros, griegos, turcos, tártaros), alumbre, algodón, cobre, cera, almácigo... (Del Treppo, 1972: 68-74).

A partir de 1415 empezó la etapa de dificultades que abocarían a una franca decadencia a partir de la guerra civil de 1462-1472. Se puede discutir, con Del Treppo, si estas dificultades no fueron en algún momento superadas largamente, pero es evidente que las razones estructurales que dificultaron primeramente e hicieron decaer después el comercio oriental ya estaban presentes. En realidad ya lo estaban antes, pero a partir de 1415 se hicieron notar con más fuerza.

Para entenderlas hemos de volver de nuevo al interior de Asia, donde en 1370 Tamerlán inició a sangre y fuego la reconstrucción del Imperio mongol. En 1395 saqueó la colonia genovesa de Tana, en Crimea, y en $1401 \mathrm{Da}$ masco, llevándose hacia el interior de Asia muchos de los artesanos de la ciudad. Todavía peor, a su muerte (1405) el Imperio se descompuso en medio de una serie de luchas que arruinaron definitivamente Asia central y rompieron los contactos con China; la ruta de las estepas prácticamente desapareció; su pérdida preludiaba claramente el hundimiento del Imperio bizantino.

Como contrapartida, las rutas meridionales se revitalizaron: imposibles los caminos de las estepas y liquidado el reino de la Pequeña Armenia, las vías que abocaban a Damasco y a Egipto quedaban como únicos nexos con el comercio oriental. Pero estas ventajas no impidieron que Egipto sufriese una profunda crisis económica; según Ashtor (1978), la rapacidad de la casta militar dominante de los mamelucos había esquilmado y dejado sin capacidad de reacción al país. A partir de los primeros años del siglo xv se observa en Egipto el abandono del uso de las ropas de lino por tejidos de lana, 
más bastos, pero más baratos. Hecho que precisamente ofreció a los catalanes una oportunidad en medio de la situación de decadencia general: la pañería flamenca o florentina de lujo no encontraba compradores, pero en cambio los paños catalanes (como los ingleses) representaban en la época la mejor relación calidad/precio (Ashtor, 1976 a), hasta el punto que también los venecianos los adquirían en Sicilia para llevarlos a Egipto (Bresc, 1983).

Sin embargo, junto a este factor favorable, una serie de causas reales o supuestas explican la decadencia del comercio catalán con Oriente. Se han señalado básicamente cuatro, que examinaremos muy rápidamente. Se trata de la piratería, la intromisión real en la navegación, como consecuencia de la empresa napolitana de Alfonso el Magnánimo, la protección dada por el mismo rey al comerciante francés Jacques Coeur y la caída de Constantinopla.

Examinémoslas rápidamente. A partir de finales del siglo xIv los catalanes se convirtieron en los piratas más numerosos y temidos en el Mediterráneo oriental, aunque no eran ni mucho menos los únicos. Se trata de un fenómeno tan documentado como oscuro en sus orígenes; adelantaré que, a mi parecer, la difusión de la piratería catalana en Oriente fue, en una parte importante, una consecuencia residual de la gran compañía almogávar, sobre todo tras la pérdida de los últimos territorios de Atenas y de Neopatria (1390); y que a menudo no se trataba tanto de catalanes como de súbditos italianos del rey de Aragón, como en el caso de uno de los corsarios más conocidos, el príncipe de Tarento (Giovanni Antonio Orsini). Lo importante no es, sin embargo, el origen de la piratería, sino su incidencia sobre el comercio. A partir de los estudios de Nuria Coll (1956) se ha venido admitiendo que la piratería comportó represalias y expulsiones contra los comerciantes catalanes y fue la causa o una de las causas de su decadencia comercial (Ashtor, 1974). Tan sólo Del Treppo (1972: 42-47) discrepa de esta opinión, basándose en una crónica contemporánea, la del veneciano Emmanuele Piloti. Este, y tras él Del Treppo, consideraba la pirateria más bien como una respuesta adecuada a la prepotencia de los mamelucos, que a menudo no respetaban tratados ni privilegios y que no entendían otro argumeiıo que la fuerza. De hecho lo que hizo importante la piratería catalana no fueron los corsarios particulares, sino la instauración como medida de presión económica de una piratería oficial o semioficial. Piloti elogia la decisión de los catalanes de devolver golpe por golpe y de hacer ver a los sultanes que podían salir malparados en el juego de represalias.

De hecho, las expulsiones y prohibiciones contra los mercaderes catalanes se repetían tan a menudo que hacen evidente su escasa duración: un primer incidente en 1408 y otro en 1414 conllevaron la confiscación de los bienes 
de todos los mercaderes catalanes y la prohibición de comerciar en el futuro; pero la marejada no debió durar mucho. En 1422 un nuevo ataque pirático volvía a provocar su expulsión y la prohibición de comerciar, aunque fuese con naves genovesas o venecianas. La respuesta catalana fue el saqueo de Beirut (1432) y de otros puertos de Siria por parte de dos expediciones piráticas prácticamente oficiales.

El saqueo de Beirut habría significado, según los autores clásicos, la proscripción definitiva de los catalanes de los territorios musulmanes, pero lo que realmente se produjo, tras la expulsión inicial de rigor, fue una apertura de negociaciones que acabó en 1430 con un tratado de paz entre Alfonso el Magnánimo y el sultán. Con todo, las relaciones comerciales ya se habían reanudado, a pesar de la guerra. En 1428 la nave de Nicolau Julià había recibido un salvaconducto para ir a Alejandría, pero una vez allí, embarcación, mercaderes y mercancías habían sido presa de los funcionarios mamelucos; el tratado de paz se ocupó de solventar el incidente.

La paz de 1430 es de la mayor importancia para la argumentación de Del Treppo. Entre otras muchas cláusulas establecía que la responsabilidad no sería colectiva, sino individual, o sea que el sultán no tomaría represalias contra los mercaderes a causa de las andanzas de los corsarios; los catalanes recibían, además, el derecho a un trato prioritario en las operaciones de aduana, de forma que serían despachados antes que los otros mercaderes europeos. Con esta base, Del Treppo puede afirmar que el comercio y el corso podían prosperar al mismo tiempo. O, como decía Piloti, por haber la nación catalana plantado cara a los sultanes, éstos reconocían su potencia, comportamiento que ponía como ejemplo a otras potencias «qui se laissent battre et malmener du souldain» (citado por Del Treppo, 1972: 45).

Con todo, discrepo de la opinión de Del Treppo, quien parece opinar que la piratería fue más beneficiosa que dañina para el comercio catalán. La imprevisibilidad de las situaciones obligó a que la mayor parte de los viajes a Oriente acabaran en Rodas y que a menudo el comercio.con Egipto hubiese de ser indirecto; difícilmente los beneficios del corso podían equilibrar estas pérdidas. Sin ser causa primordial de la decadencia, y siendo quizá a menudo inevitable, es evidente que la piratería y la ruptura de relaciones diplomáticas y comerciales que a menudo representaba, con largas retenciones o pérdidas de capitales, mercancías y vidas humanas, no fueron de ninguna ayuda para el mantenimiento del comercio catalán.

Del Treppo, que no da mucha importancia a la piratería, atribuye mucha más a la retención de grandes fuerzas navales en el Mediterráneo occidental a partir de 1433, como consecuencia de la lucha por el reino de Nápoles, que no fue un paseo militar como había sido la empresa de Sicilia, sino una dura 
guerra de desgaste, con la derrota de Ponza (1435) y con largas campañas hasta alcanzar el éxito final de 1443. Podríamos preguntarnos, sin embargo, si se trata tanto de decandencia del comercio como de disminución de los medios de transporte naval ${ }^{12}$. Una vez acabadas las hostilidades, el número de viajes a Oriente fue en aumento; señal, por tanto, de que mercaderes y mercancías existían y de que las condiciones no habían variado; en cambio, cuando Alfonso el Magnánimo emprendió nuevas aventuras en Italia la navegación catalana hacia Oriente volvió a decaer.

Más importante que las razones anteriores fue seguramente la actuación del mercader y financiero francés Jacques Coeur. No a causa de la protección que pudiera recibir del rey, que no iba más allá de la que cualquier monarca de la época utilizaba para atraerse la benevolencia de un embajador extranjero, sino por el hecho de haber convencido al rey de Francia de que era posible incrementar la actividad del puerto de Marsella asegurándole el monopolio del mercado de las especias en Provenza y en Occitania si se tomaban las medidas aduaneras pertinentes para hacer desaparecer del mercado a los anteriores redistribuidores genoveses y catalanes ${ }^{13}$. A partir de 1449 la ruta de las especias comenzó a declinar claramente y lo haría todavía más tras la caída de Constantinopla (Del Treppo, 1976: 51). Pero el golpe definitivo al comercio catalán con Oriente provino de la guerra civil (1462-1472), con la destrucción de capitales y de medios de transporte, el corso a que se libraron los dos bandos y la pérdida de mercados que representó. Ahora bien, aunque Del Treppo (1972: 538-539) discrepe de ello, argumentando que hay un salto cualitativo entre la crisis de preguerra y el arrasamiento que el conflicto representó para el comercio catalán en el plano internacional, no hay que olvidar que -como dice Vilar (1962: II, 199)— la guerra sale de la crisis. En caso contrario, Mallorca y, sobre todo, Valencia habrían podido coger el relevo, hecho que no se dio. Ciertamente en el decenio de 1450 se produjo un importante grupo de iniciativas que cabría etiquetar como mercantilistas: expulsión de comerciantes extranjeros, impulso a la construcción naval, prohibición de embarcar mercancías en naves extranjeras, envío a Oriente de la flota de Bernat Vilamarí, introducción de cláusulas favorables al comercio en todos los tratados diplomáticos con los jefes de los Balkanes amenazados por los turcos... (Del Treppo, 1972: 419 y 550.551; Carrère,

${ }^{12} \mathrm{Ya}$ desde finales del siglo xIv, la marina catalana parece haber sido insuficiente o poco competitiva; repetidamente fueron fletadas hacia Levante naves extranjeras: castellanas, vizcaínas, genovesas o florentinas (Del Treppo, 1972). La escasez de naves fue reconocida por el representante del Consolat de Mar en las Cortes de Monzón de 1435-1436 (Carrère, 1967: II, 220-222 y 238).

${ }^{13}$ Básicamente, una imposición del 10 por 100 sobre las especias entradas en Francia, salvo por el puerto de Aigües Mortes, y en naves francesas. 
1967: II, 385), pero hace falta recordar que cuando una economía reclama la ayuda estatal acostumbra a significar que las cosas no van demasiado bien.

En todo caso la guerra civil representó la decadencia definitiva, a pesar de los desesperados esfuerzos para no abandonar ${ }^{14}$ : incremento de la presencia militar, nuevos pactos con Egipto, mantenimiento del consulado de Constantinopla bajo el poder turco, formación, en 1495, de una gran compañía comercial para el comercio con Alejandría... Pero de 1461 a 1493 Del Treppo sólo documenta 43 viajes y de ellos 34 acabaron en Rodas. Y es que existe una última causa de decadencia, no señalada más que por Ashtor (1978) y aun de pasada: el Egipto de los mamelucos estaba tan esquilmado que carecía casi por completo de capacidad de compra; había que acudir con dinero o algunos metales estratégicos, como cobre o hierro; el resto de las mercancías no encontraba compradores. Solamente Venecia estaba en disposición de mantener un comercio en estas condiciones.

La decadencia se debió, pues, básicamente a la ruina y a la pérdida de mercados causados por la guerra civil, pero también a la decadencia de Egipto. Ya no había negocio de ida y vuelta, sino sólo de vuelta, y los catalanes no disponían de capitales suficientes para mantenerlo, sobre todo tras la pérdida del mercado occitano. Más tarde la llegada de los portugueses a la India y el desvío de la ruta de las especias hicieron el resto; pero todavía en 1537 se llevó a cabo una expedición y en 1539 fue nombrado el postrer cónsul catalán en Alejandría. Los últimos restos se desvanecieron con la ocupación turca de Quíos en 1566, donde todavía permanecía abierto el consulado, y de una manera definitiva en 1571 , tras el choque de Lepanto.

Interacción de la política y de la economia en la expansión mediterránea

Vicens Vives (1940: 111; 1957: 64), con una de las magníficas intuiciones que le caracterizaban, encuñó la expresión «diagonal de las islas" para describir la expansión mediterránea de la Corona de Aragón e insinuó que esta profundización en el Mediterráneo podía tener relación con el deseo de dominar la ruta de las especias. La idea, aceptada entre otros por Pierre Vilar (1962), ha sido muy divulgada $y$, en los últimos años, también discutida (Portella, 1979; Ruiz Doménech, 1980; Hillgarth, 1984).

Una revisión detallada del tema alargaría en exceso esta nota; nos limitaremos, pues, a hacer algunas indicaciones muy sintéticas sobre la cuestión.

En la conquista de Mallorca los móviles comerciales iban apareados con

${ }^{14}$ En plena guerra civil, en 1467, Bernat de Vilamarí se presentó con su escuadra ante Damieta y forzó un nuevo tratado comercial. 
el expansionismo de la clase feudal, hasta el punto de dar origen a una conflictiva sociedad dual entre entre la ciudad-emporio comercial y el campo rudamente feudalizado; en todo caso Mallorca era más bien un puente hacia el norte de Africa que una punta de lanza hacia Oriente.

La conquista de Sicilia en 1282 fue debida, como dice Hillgarth (1984), a intereses puramente dinásticos que sirvieron de trampolín a los sicilianos para librarse de la dominación angevina. Pedro el Grande se limitó a aprovechar una ocasión que no parece haber promovido. Precisamente por el protagonismo nativo en la sublevación (las Visperas Sicilianas) no se creó para los comerciantes catalanes una expectativa de ganancias comparable al caso de Mallorca. De hecho, los mercaderes catalanes no recibieron el primer privilegio en la isla hasta seis años después de la conquista, cuando ya Sicilia se había convertido en reino independiente; aunque poco a poco los mercaderes catalanes fueron adquiriendo posiciones de privilegio frente a los mercaderes y productos del norte de Italia.

Aunque sobre el mapa Mallorca y Sicilia señalen una hermosa diagonal desde Cataluña hacia el Mediterráneo oriental, cualquier hipótesis de apoyo político como base para un dominio económico se viene abajo ante la evidencia de la separación de la formación de reinos independientes en ambas islas. La unión posterior fue debida, en el caso de Sicilia, al azar de las herencias sucesorias. ¡Resulta difícil imaginar una diagonal sobre tres soberanías distintas!

Los hechos posteriores no parecen abonar ningún interés efectivo en dominar posiciones más cercanas a la ruta de las especias; solamente la boda de Jaime II con María de Lusignan, heredera de Chipre (1315), podía hacer pensar en un intento de futura incorporación, pero cuando podian haber reclamado dicha corona (1324), los monarcas catalanes no lo hicieron. Hecho sintomático: si no lo hicieron fue seguramente porque justo el año antes se había iniciado la difícil conquista de Cerdeña, y el dominio de la isla del Tirreno debió parecer de mayor interés que la lejana Chipre, aún aureolada con el título de reino de Jerusalén. Cerdeña era importante por su riqueza (trigo, coral), por el mercado que podía representar para los productos catalanes y sobre todo por su situación estratégica; los comerciantes catalanes tuvieron una parte importante en la preparación y financiación de la campaña (Hillgarth, 1984: 105). Cerdeña resulta algo apartada de la diagonal de las islas, pero representaba una eficaz barrera frente a los genoveses. De ahí que en torno a la isla se librara una larga guerra de desgaste encomendada básicamente por uno y otro bando a los ataques corsarios y completada por repetidas sublevaciones internas. Pero entre tanto los catalanes lograron conquistar las pequeñas islas del canal de Sicilia (Malta, Gozzo, 
Pantelaria, Djerba) y casi monopolizaban el tráfico entre Sicilia y Túnez. Igualmente sus preocupaciones militares se dirigían a mantener, bajo un protectorado rayano en la sumisión, a los pequeños estados del norte de Africa (Dufourcq, 1966).

La expedición almogávar (iniciada en 1303) tampoco tuvo nada que ver con cuestiones comerciales (ni prácticamente tampoco con la Corona de Aragón), de forma que nunca se pensó en aprovecharla para obtener una base naval en el Egeo, cosa que habría resultado francamente fácil y que contaba con los ejemplos de Quíos y de Rodas.

Por tanto, en el siglo XIV no parece que se pueda hablar de diagonal de las islas como trampolín para la ruta de las especias. El interés de la monarquía se centraba más bien en conseguir una especie de camino de ronda en el Mediterráneo occidental, aunque ni siquiera aquí los territorios no peninsulares estaban siempre bajo el dominio directo de la corona.

Queda un segundo momento: la época de Alfonso el Magnánimo y su política para evitar a la vez las amenazas de los turcos y de los mamelucos. En este caso sí se observa una preocupación por el mantenimineto del cordón umbilical Sicilia-Rodas-Chipre (Vicens Vives, 1956: 139-141). Se mandó a Oriente una escuadra, la de Bernat de Vilamarí, con base primeramente en Chipre y más tarde en la pequeña isla de Castellorizzo (Castellroig), ocupada y fortificada a partir de 1450. Podríamos añadir el intento posterior de llevar al trono de Chipre un infante siciliano, pero las maniobras de la colonia catalana en la isla no recibieron ningun ayuda oficial, y finalmente Chipre cayó en manos de Venecia.

En realidad toda la política oriental estuvo siempre subordinada a la empresa de Nápoles, que tuvo absoluta preferencia en la asignación de recursos y energías por parte del Magnánimo, lo cual era, por otra parte, perfectamente lógico si tenemos en cuenta el valor económico y estratégico (e incluso cultural) del reino de Nápoles, en comparación con la inseguridad del éxito y la endeblez comparativa de los rendimientos esperables de cualquier empresa en el Mediterráneo oriental o en los Balkanes. En este ámbito se hicieron, pues, en conjunto, muy pocos esfuerzos y muy tardíos para poder hablar de la existencia de una expansión militar pensada como base para el comercio con Oriente. El brazo político de la Corona alcanzaba solamente al Mediterráneo occidental. Más allá el comercio corría su propio riesgo. 


\section{BIBLIOGRAFIA}

Airaldi, Gabriela (1983): «Groping in the dark: the emergence of Genoa in the early middle ages», Miscellanea di Studi Storici Genova, II.

AshtoR, Elihayu (1974): «The Venetian Supremacy in Levantine Trade; Monopoly or Pre-colonialism?", The Journal of European Economic History, 3, 1.

- (1976 a): «Les lainages dans l'Orient Médieval... Emploi, production, commerce», en Atti de la Seconda Settimana de Studio. Istituto F. Datini, Florencia, 1976; reproducido en Studies in Levantine Trade in the Middle Ages, Londres, 1978.

- $(1976 b)$ : "Observations on Venetian Trade in the Levant in the xivth Century", The Journal of European Economic History, 5, 3.

- (1978): «L'exportation de textiles occidentaux dans la Proche Orient musulman au bas Moyen Age (1370-1517)m, en Studi in memoria di Federigo Melis, vol. II.

Bresc, Henri (1983): «La draperie catalane au miroir sicilien, 1300-1460», Acta Historica et Archaeologica Mediaevalia, 4.

Campmany, Antonio de (1779): Memorias bistóricas sobre la marina, comercio y artes de la antigua ciudad de Barcelona, Madrid; reeditada en Barcelona, 1961-1963.

Carrere, Claude (1967): Barcelone centre économique à l'époque des difficultés, 13801462, París-La Haya; traducción catalana con el título Barcelona, 1380-1462. Un centre econòmic en època de crisi, Barcelona, 1977, por la cual citamos.

Cols, Nuria (1954): «Aspectos del corso catalán y del comercio internacional en el siglo Xv», Estudios de Historia Moderna, IV.

Dufource, Charles-E. (1966): L'Espagne catalane et le Magbrib aux XIII et XIV siècles, París; traducción catalana con el título L'expansió catalana a la Mediterrània occidental. Segles XIII i XIV, Barcelona, 1969.

Garcí Sanz, Arcadi, y Ferrer i Mallol, M:" Teresa (1983): Assegurances $i$ canvis maritims medievals a Barcelona, Barcelona, Institut d'Estudis Catalans, 2 vols.

HeErs, Jacques (1963): L'Occident aux XIV et XV siècles. Aspectes Economiques et sociaux, París; traducción castellana con el título Occidente durante los siglos XIV y XV, Barcelona, 1968, por la cual citamos.

HEYD, Wilhelm (1879): Geschichte des Levantbandels in Mittelalter, Stuttgart; traducción italiana con el título Storia del commercio del Levante nel medio evo. Turín, 1913 , por la cual citamos.

Hillgarth, J. M. (1984): El problema d'un Imperi Mediterrani català, Palma de Mallorca.

LOPEZ, Robert S. (1952): *The Trade of medieval Europe: the South , en Cambridge Economic History of Europe, tomo II, Londres; traducción castellana: «El comercio en la Europa medieval: el Sur», en Universidad de Cambridge, Historia económica de Europa, II: El comercio y la industria en la Edad Media, Madrid, 1967, por la cual citamos.

- (1971): The commercial revolution of the middle ages, Englewood Cliffs; traducción castellana con el título La revolución comercial en la Europa medieval, Barcelona, 1972.

LÓPEZ DE MENESES, Amanda (1956): «Los consulados catalanes de Alejandría y Damasco», Estudios de Edad Media de la Corona de Aragón, 6.

Madurell, Josep M.:, y García Sanz, Arcadio (1978): Comandas comerciales barcelonesas de la Baja Edad Media, Barcelona.

MASIA DE Ros, Angeles (1951): La Corona de Aragón y los Estados del Norte de Africa, Barcelona.

Nicolau D'Olwer, Lluís (1926): L'expansió catalana a la Mediterrània oriental, Barcelona.

Pistarino, Geo (1979): «Economia e società nel Mediterraneo orientale all'epoca di Giacomo I il Conquistatore», en VV. AA., Jaime I y su época. X Congreso de Historia de la Corona de Aragón, Zaragoza, vol. I.

Portella I Comas, Jaume (1979): «L'expansió catalana per la Mediterrània: història i ideologia", L'Avenç, 16.

RuBió I Lluch, Antoni (1947): Diplomatari de l'Orient catald, Barcelona. 
Ruiz Domenech, José Enrique (1980): «Ruta de las especias y ruta de las islas. Apuntes para una nueva periodización», en Actas del I Congreso Internacional de Historia Mediterránea. Palma de Mallorca, 17-22 de diciembre de 1973. La Peninsula Ibérica y el Mediterráneo centro-occidental (siglos XII-XV), Madrid-Barcelona.

SAYous, André-E. (1975): Els mètodes comercials a la Barcelona medieval (introducción de Arcadi García Sanz y Gaspar Feliu Montfort), Barcelona.

Trenchs Odena, Josep (1980): «De Alexandrinis (El comercio prohibido con los musulmanes y el papado de Aviñón durante la primera mitad del siglo xIv)», en Actas del I Congreso Internacional de Historia Mediterránea. Palma de Mallorca, 17-22 de diciembre de 1973. La Peninsula Ibérica y el Mediterráneo centro-occidental (siglos XII-XV), Madrid-Barcelona.

TREPpo, Mario del (1972): I mercanti catalani e l'espansione della Corona d'Aragona nel secolo XV, Nápoles; traducción catalana con el título Els mercaders catalans i l'expansió de la Corona catalano-aragonesa, Barcelona, 1976, por la cual citamos.

Vicens Vives, Jaume (1940): España. Geopolítica del Estado y del Imperio, Barcelona.

- (1956): Els Trastàmares (segle XV), Barcelona.

- (1959): «La economía de los países de la Corona de Aragón en la Baja Edad Media», en VI Congreso de Historia de la Corona de Aragón (Cagliari-Alguer, 8-14 de diciembre de 1957), Madrid; republicado en Coyuntura económica y reformismo burgués, Barcelona, 1968.

Voltes Bou, P. (1964): «Repertorio de documentos referentes a los cónsules de Ultramar y el Consulado del Mar conservados en el Instituto Municipal de Historia de Barcelona», Documentos y Estudios, XIII. 